Brit. J. industr. Med., 1961, 18, 287.

\title{
THE DISTRIBUTION AND EXCRETION OF INHALED MERCURY VAPOUR
}

\author{
BY \\ J. C. GAGE \\ From Imperial Chemical Industries Limited, Industrial Hygiene Research Laboratories, The Frythe, \\ Welwyn, Herts
}

(RECEIVED FOR PUBLICATION FEBRUARY 22, 1961)

\begin{abstract}
Rats have been exposed for varying periods to an atmosphere containing $1 \mathrm{mg}$./cu.m. mercury vapour. The toxic effects produced showed resemblances to signs of mercurialism in man. An attempt has been made to study the kinetics of absorption and excretion of mercury from measurements of the amounts excreted and stored in the tissues.

The efficiency of absorption of mercury by the rat lung is about $50 \%$. A small proportion is excreted into the gut. After about 10 days of continuous exposure a steady state is reached in which excretion balances absorption. During short exposures the turnover of mercury in all tissues except brain is fairly rapid and most of the mercury is cleared from the body within a week after exposure. The urinary excretion of mercury, during the initial stage of storage in the tissues and the final stage of clearance, shows divergencies from the simple exponential pattern; there appears to be a delay mechanism in the kidney which, in intermittent exposures, may result in the occurrence of peak excretion during periods of non-exposure. After more prolonged exposures the mercury in the kidney appears to be converted to a form which is only very slowly excreted.

The significance of the urinary excretion of mercury by man after industrial exposure to mercury vapour is discussed. The rat experiments suggest that single measurements will give only limited information concerning industrial conditions, but that an approximate assessment of the total absorbed during a working week would be obtained if it were possible to make a seven-day collection of urine. Repeated measurements after exposure would yield information on the duration of exposure and would have some diagnostic value.
\end{abstract}

The quantitative determination of mercury in urine admits considerable sensitivity and specificity and numerous attempts have been made to utilize such measurements in the control of human industrial exposure to mercury vapour. A review on this subject by Heyroth (1949) is not, however, very encouraging and the opinion of most investigators appears to be well summarized by his comment that the elimination of mercury in the urine is too irregular to be of value in determining the severity of occupational exposure, and its absence from urine in occasional typical cases of mercury poisoning makes a search for it of uncertain value as a means of determining that exposure has occurred previously. More recent investigations have indicated some measure of correlation between urinary excretion of mercury and signs of mercury poisoning, but very wide individual variations in excretion obscure the interpretation of urine analysis (Turrian, Grandjean, and Turrian, 1956; Totušek and Waelschová, 1954).

A study of the earlier literature tends to confirm Heyroth's opinion that uncertainty regarding the validity of the analytical methods renders much of the work of doubtful significance. Modern methods are more reliable and although it is still possible for errors to be introduced, it seems unlikely that the present uncertainty concerning the interpretation of urinary mercury concentrations can be attributed to analytical errors. It seems more probable that the excretion of mercury follows a complex pattern which has not yet been revealed by experimental studies on man or animals, and a simple interpretation cannot be based on the analytical results.

The first step in elucidating the excretion of mercury in man would be a detailed knowledge of the fate of inhaled mercury in an experimental 
animal. Extensive investigations have been undertaken by Ashe, Largent, Dutra, Hubbard, and Blackstone (1953), in which a variety of species was exposed to known mercury concentrations in air, but their experiments were directed primarily to the establishment of a threshold concentration for the appearance of the toxic effects. The protocols of these experiments yield only limited information concerning the balance between mercury absorbed and mercury eliminated and the rates of accumulation and excretion. A study of the kinetic aspects of the fate of inhaled mercury has, therefore, been undertaken, using the rat as the experimental animal; observations have also been made on the progress of signs of mercury poisoning under controlled conditions.

\section{Preparation of Mercury Vapour Atmospheres}

A current of nitrogen $(0.31 . / \mathrm{min}$.) was passed over the surface of $100 \mathrm{ml}$. mercury contained in a $500 \mathrm{ml}$. round-bottom flask, heated by means of an electric mantle to $180^{\circ} \mathrm{C}$. The nitrogen was then passed through a filter thimble to remove any condensed mercury droplets and diluted 15 to 20 -fold with clean air. This dilution was passed through a vessel in which it was mixed by turbulence; it was then daily analysed by the method described below and the air-flow adjusted if necessary to give a concentration of $1.0 \pm 0.1 \mathrm{mg}$./cu.m. mercury.

The mercury concentration in the atmosphere was determined by absorption in acid-permanganate followed by a modification of the dithizone titration method of Fabre, Truhaut, and Boudène (1958). A 2-litre sample of the atmosphere was aspirated at a constant speed of $11 . / m i n$. through a bubbler containing a mixture of $8 \mathrm{ml} .6 \% \mathrm{w} / \mathrm{v}$ aqueous potassium permanganate and $2 \mathrm{ml}$. $50 \% \mathrm{v} / \mathrm{v}$ aqueous sulphuric acid. The solution so obtained was decolorized with $2 \mathrm{ml}$. $20 \%$ aqueous hydroxylamine hydrochloride solution, and $2 \mathrm{ml} .10 \%$ $\mathrm{w} / \mathrm{v}$ aqueous urea solution and $1 \mathrm{ml} .2 .5 \% \mathrm{w} / \mathrm{v}$ ethylenediamine tetra-acetic acid disodium salt solution were added. A control solution was prepared by mixing the same amounts of all of the above reagents in a tube similar in shape to that used in the bubbler. Both solutions were adjusted to $p \mathrm{H} 1 \cdot 5$, using external indicator paper and a solution of sodium acetate prepared by mixing the crystalline salt with an equal weight of water. A dilute dithizone solution was prepared by diluting a stock $20 \mathrm{mg}$. \% solution in carbon tetrachloride 1 to 20 with chloroform; the test solution was titrated with this dithizone solution, added in small portions from a burette followed by vigorous shaking of the stoppered tube, until the separated lower organic layer developed a colour intermediate between the green of dithizone and the orange of the mercury-dithizone complex. The volume of dithizone solution required for the test solution was noted and the same volume added to the control tube. The latter was then titrated with a standard aqueous solution containing $1 \mu \mathrm{g} . / \mathrm{ml}$. mercury, added in small portions followed by vigorous shaking, until by visual comparison the colours of the separated organic layers in the two tubes were identical. The titration figure gave the mercury content of the air sample expressed in $\mu \mathrm{g}$. Analytical quality reagents were used in this determination. The efficiency of this method of analysis was demonstrated by making an estimation with a second bubbler containing acid permanganate in series with the first; no mercury could be detected in the second bubbler.

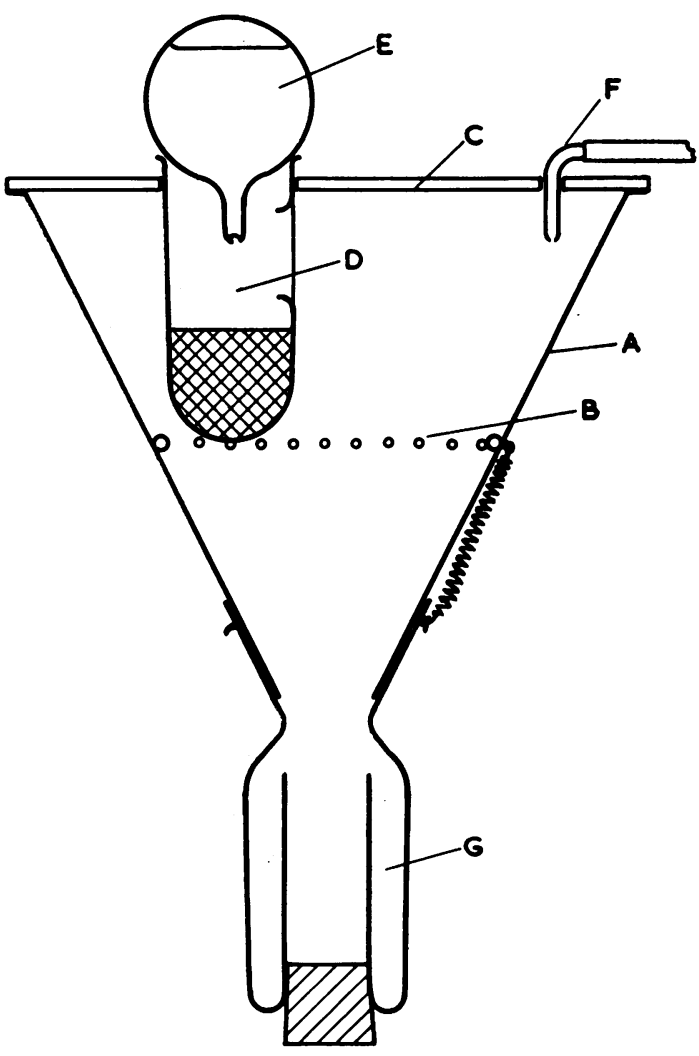

FIG. 1.-Diagram of cage for exposing individual rats to mercury vapour. A, polyethylene funnel; $B$, stainless steel wire grid; C, "Perspex" lid; D, feeding tube; E, water bottle; F, inlet for mercury atmosphere; G, separator for collecting urine and faeces.

\section{Exposure of Experimental Animals}

Albino Wistar strain female rats, average initial weight $160 \mathrm{~g}$., were housed in the individual metabolism cages shown in Fig. 1. They were supported on a stainless steel wire grid inserted in a $20 \mathrm{~cm}$. diameter polyethylene funnel covered with a "Perspex" lid through which passed the glass feeding tube and a water bottle. The feeding tube was $4 \mathrm{~cm}$. diameter and $8 \mathrm{~cm}$. long and contained a one-day supply of ground rat cube moistened with water to a paste, and it was pierced with a $3 \mathrm{~cm}$. diameter hole bearing an internal flange which was sufficiently large to permit the entry of a rat's head 
TABLE 1

RECOVERY OF MERCURY ADDED TO NORMAL RAT TISSUES AND EXCRETA; ALL SAMPLES CONTAINED INITIALLY NEGLIGIBLE AMOUNTS OF MERCURY

\begin{tabular}{|c|c|c|c|c|}
\hline \multirow{2}{*}{ Material } & \multirow{2}{*}{$\begin{array}{l}\text { Amount Taken } \\
\text { for Analysis } \\
\text { (g.) }\end{array}$} & \multicolumn{2}{|c|}{ 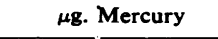 } & \multirow{2}{*}{$\%$ Recovery } \\
\hline & & Added & Found & \\
\hline $\begin{array}{l}\text { Kidney } \\
\text { Liver } \\
\text { Spleen } \\
\text { Brain } \\
\text { Lung } \\
\text { Gut } \\
\text { Blood } \\
\text { Urine } \\
\text { Faeces }\end{array}$ & $\begin{array}{r}2 \\
2 \\
2 \\
2 \\
2 \\
2 \\
2 \\
10 \mathrm{ml} . \\
2\end{array}$ & $\begin{array}{l}4 \\
4 \\
4 \\
4 \\
4 \\
4 \\
4 \\
4 \\
4\end{array}$ & $\begin{array}{l}3 \cdot 7,3 \cdot 8 \\
3 \cdot 9,3 \cdot 9 \\
3 \cdot 9,3 \cdot 9 \\
3 \cdot 8,3 \cdot 9 \\
3 \cdot 6,3 \cdot 7 \\
3 \cdot 8,3 \cdot 8 \\
3 \cdot 7,3 \cdot 8 \\
3 \cdot 9,3 \cdot 9 \\
3 \cdot 0,3 \cdot 4\end{array}$ & $\begin{array}{l}94 \\
97 \\
97 \\
96 \\
94 \\
95 \\
94 \\
97 \\
80\end{array}$ \\
\hline
\end{tabular}

without allowing it to withdraw any of the diet. Rats exposed in these cages to a mercury-free atmosphere for five days a week showed a weight increase over a period of seven weeks similar to that of rats kept under normal conditions, though during the first few weeks the weight gain while in the metabolism cage was less than normal, with recovery over the week-ends. This could be correlated with an initial reduced food intake in the metabolism cage.

The test mercury atmosphere passed through a manifold to each of six metabolism cages, entering through a hole in the lid. The excreta were collected in a glass separator shown in Fig. 1, constructed from two concentric tubes, the faeces falling in the inner tube and the urine trickling down the funnel and collecting in the annular outer chamber. This type of separator has been in use for many years in this laboratory and has the advantages of robustness and simplicity of construction; if required it may be placed in a vacuum flask containing solid carbon dioxide which freezes the urine as soon as it enters the separator.

\section{Analysis of Excreta and Tissues}

Oxidation with Acid Permanganate.-The urine was well mixed, diluted if necessary, and $10 \mathrm{ml}$. were measured into a glass-stoppered tube. To this were added 2 $\mathrm{ml} .50 \% \mathrm{v} / \mathrm{v}$ sulphuric acid, $0 \cdot 5 \mathrm{~g}$. potassium permanganate and a few drops of octanol. The tube was heated in a boiling water bath, with the stopper loosely inserted, for 30 minutes. A $2 \%$ homogenate of the total daily faeces was prepared in water by means of a macerator and a $100 \mathrm{ml}$. portion was measured into a $250 \mathrm{ml}$. roundbottomed flask and $10 \mathrm{ml}$. sulphuric acid, $5 \mathrm{~g}$. potassium permanganate, and a few drops of octanol were added. A water-cooled condenser was attached by means of a standard-taper joint and the contents of the flask were boiled on an electric mantle for three hours. The procedure used for tissues was similar to that for faeces, except that a $5 \%$ homogenate was prepared. The control solution was prepared by heating to the boiling point a volume of acid-permanganate equal to the volume of homogenate used, decolcrizing with hydroxylamine hydrochloride, and precessing as above.

Determination of Mercury Content.-A slight excess of solid hydroxylamine hydrochloride was added to the hot solution after permanganate oxidation which was then
TABLE 2 MERCURY CONTENT OF TISSUES, EXPRESSED IN $\mu \mathrm{g}$. $1 \mathrm{mg} . / \mathrm{cu} . \mathrm{m}$. MERCURY (AVERAGE OF FOUR RATS)

\begin{tabular}{l|c|c|c}
\hline \multirow{2}{*}{ Tissue } & \multicolumn{3}{c}{ Period After Exposure (days) } \\
\cline { 2 - 4 } & 0 & 2 & 4 \\
\hline Lungs & $17 \cdot 5$ & $8 \cdot 2$ & $6 \cdot 7$ \\
Liver & 25 & $5 \cdot 1$ & $2 \cdot 3$ \\
Kidneys & 222 & 155 & 137 \\
Spleen & $0 \cdot 8$ & $0 \cdot 6$ & 0.2 \\
Brain & $9 \cdot 8$ & $13 \cdot 8$ & $13 \cdot 3$ \\
Gastro-intestinal tract & $12 \cdot 8$ & $2 \cdot 7$ & $3 \cdot 7$ \\
Blood (estimated)* & $4 \cdot 4$ & $3 \cdot 0$ & $1 \cdot 4$ \\
Muscle (estimated) $\dagger$ & 11.4 & $11 \cdot 3$ & 0 \\
\hline Total & 304 & 200 & 165 \\
\hline
\end{tabular}

*Calculated assuming $10 \mathrm{ml}$. blood per rat.

†Calculated assuming $43 \%$ body weight.

filtered if necessary. After cooling, all or part of the solution was taken and the analysis completed as described above for the determination of mercury in the test atmosphere. Recoveries of known amounts of mercury added to normal rat tissue and excreta are shown in Table 1.

\section{Experimental Results on Rats}

Continuous Exposure.-A group of 12 rats was exposed 24 hours a day, for a period of 28 days to the $1 \mathrm{mg}$./cu.m. concentration of mercury vapour. All the rats survived this exposure but showed a loss in weight over the period. The rats became lethargic by the seventh day and at the termination of the exposure they were showing slight tremors when lifted by their tails. Pooled urine and faeces were collected from the rats each day; at the end of the exposure period four of the rats were killed, and at intervals of two days the remaining rats were killed in groups of four. Tissues were removed from these rats for mercury analysis. The results obtained are shown in Table 2; the figures for blood and muscle are based on the assumptions that each rat contained $10 \mathrm{ml}$. blood and that the skeletal muscle constituted $43 \%$ of the body weight (Donaldson, 1924). The whole gastro-intestinal tract was removed and washed through with water before analysis. The daily excretion of mercury in urine and faeces by these rats is shown in Fig. 2 .

In order to study the retention and excretion of mercury in the initial stages of continuous exposure, the experiment was repeated with a group of 12 rats. Urine was collected each day and at two-day intervals four of the rats were killed and the kidneys removed for mercury determinations. The results of this experiment are shown in Table 3.

Repeated 100-hour Exposures.-A group of six rats was exposed to the $1 \mathrm{mg}$./cu.m. mercury vapour atmosphere continuously for 100 hours from Monday to Friday in each week, for six successive 


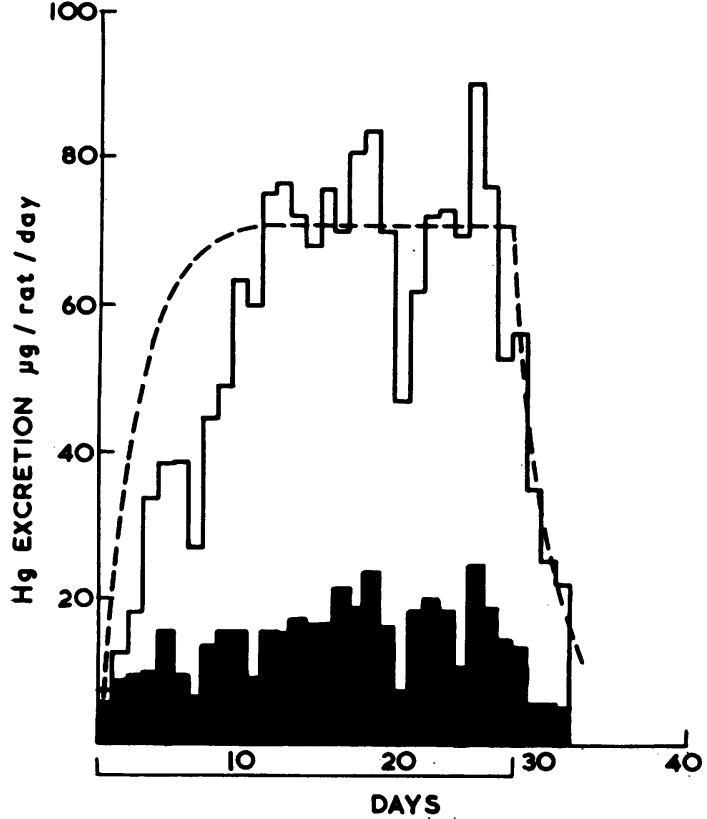

FIG. 2.-Total excretion of mercury after 28 days of continuous exposure to $1 \mathrm{mg}$./cu.m. mercury. Square bracket indicates period of exposure. Faecal excretion indicated by black area. The broken line is the curve calculated according to equations (3) and (5).

weeks. Growth during this period was retarded, the average increase per rat being about 10 grammes. By the third week of exposure the rats were in poor condition; they appeared lethargic and they squeaked when touched. After five weeks all the rats were showing fine tremors which were more noticeable when the animals were lifted by their tails. The tails themselves had an unusual rigidity.

The pooled urine was analysed for mercury four times a week, and occasional daily analyses were made during the week-ends when the rats were not exposed to the mercury atmosphere. The results are shown in Fig. 3. Two of the rats were killed at

TABLE 3

URINARY EXCRETION AND KIDNEY STORAGE OF MERCURY DURING INITIAL STAGE OF CONTINUOUS MERCURY DURING INITIAL STAGE OF CONTINUOUS
EXPOSURE TO $1 \mathrm{mg} . / \mathrm{cu} . \mathrm{m}$. MERCURY (AVERAGE OF FOUR
RATS)

\begin{tabular}{|c|c|c|c|}
\hline \multirow{2}{*}{$\begin{array}{c}\text { Duration of Exposure } \\
\text { (days) }\end{array}$} & \multicolumn{2}{|c|}{ Mercury Content ( $\mu \mathrm{g})}$. & \multirow{2}{*}{$a$} \\
\hline & Urine & Kidney & \\
\hline $\begin{array}{l}1 \\
2 \\
3 \\
4 \\
5 \\
6\end{array}$ & $\begin{array}{l}1.8 \\
6.5 \\
19 \\
50 \\
52.5 \\
53.5\end{array}$ & $\begin{array}{c}72 \cdot 5 \\
115 \\
142\end{array}$ & $\begin{array}{l}0.09 \\
0.43 \\
0.38\end{array}$ \\
\hline
\end{tabular}

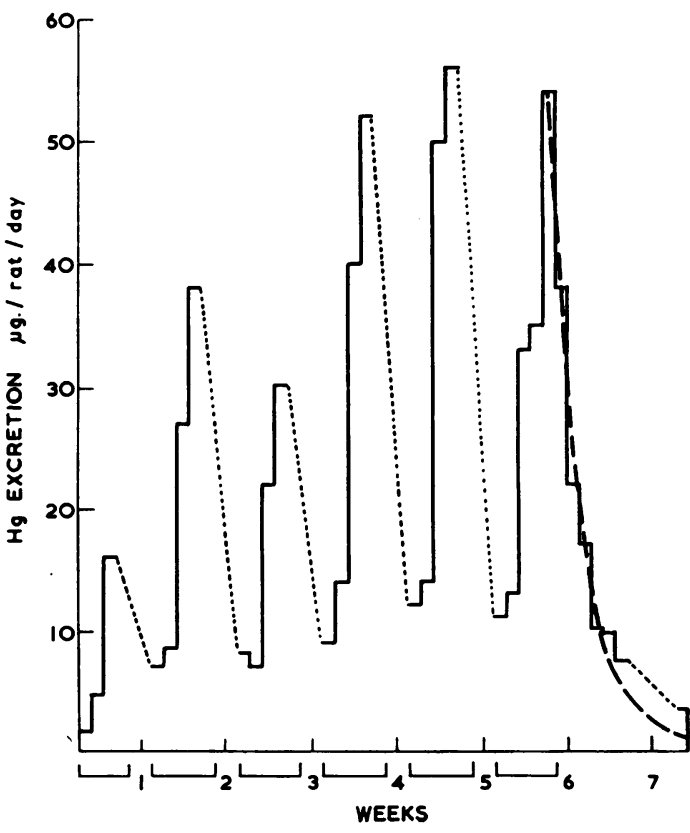

Fig. 3.-Urinary excretion of mercury after repeated 100-hour exposures to $1 \mathrm{mg}$./cu.m. mercury in successive weeks. Square brackets indicate periods of exposure. Dotted lines are periods when excretion was not measured. Broken line is the curve calculated according to equation (3).

the end of the exposure, two more three months later, and the two survivors were killed after a further three months. The mercury contents of the organs are shown in Table 4. Urine was collected from the survivors for a time after the exposure and the mercury contents are included in Fig. 3. The tremors which were observed during the exposure periods soon disappeared from the survivors but they continued to squeak when touched for several weeks. During the first weeks of the exposure the urine showed a fluctuating protein content, reaching a maximum of $0.9 \mathrm{mg} . / \mathrm{ml}$. Later during the experiment the protein excretion became very small.

TABLE 4

MERCURY CONTENT OF ORGANS FROM RATS EXPOSED MERCURY CONTENT OF ORGANS FROM RATS EXPOSED PERIODS; AVERAGE OF TWO RATS, EXPRESSED AS Mg./RAT

\begin{tabular}{c|c|c|c|c|c}
\hline $\begin{array}{c}\text { Period after } \\
\text { Exposure } \\
\text { (months) }\end{array}$ & \multicolumn{5}{|c}{ Organs } \\
\cline { 2 - 6 } \cline { 5 - 7 } & Lungs & Liver & Kidney & Spleen & Brain \\
\hline 0 & 10 & 4.6 & 137 & 0 & 8 \\
3 & 0 & 0 & 15 & 0 & 1.6 \\
6 & 0 & 0 & 1.9 & 0 & 1.4 \\
\hline
\end{tabular}


TABLE 5

INDIVIDUAL WEEKLY MERCURY EXCRETION IN URINE OF SIX RATS EXPOSED TO $1 \mathrm{mg} . / \mathrm{cu} . \mathrm{m}$. MERCURY FOR 100 HOURS/WEEK, FOR SIX WEEKS

\begin{tabular}{|c|c|c|c|c|c|c|c|c|}
\hline Week & \multicolumn{6}{|c|}{ Mercury Excretion ( $\mu$ g./Rat) } & \multirow{2}{*}{$\begin{array}{r}\text { Mean } \\
29 \cdot 1 \\
83.6 \\
85.8 \\
166.6 \\
222.1 \\
173.8\end{array}$} & \multirow{2}{*}{$\begin{array}{c}\begin{array}{c}\text { Coefficient of } \\
\text { Variation } \\
(\%)\end{array} \\
36 \cdot 8 \\
20 \cdot 5 \\
15 \cdot 5 \\
23 \cdot 8 \\
6.2 \\
17 \cdot 2\end{array}$} \\
\hline $\begin{array}{l}1 \\
2 \\
3 \\
4 \\
5 \\
6\end{array}$ & $\begin{array}{r}27 \cdot 3 \\
86.0 \\
105.6 \\
140.1 \\
221.5 \\
166.5\end{array}$ & $\begin{array}{r}29.9 \\
92.0 \\
111.8 \\
190 \\
246.3 \\
227.7\end{array}$ & $\begin{array}{r}29.9 \\
76.8 \\
81.9 \\
128.9 \\
220.1 \\
175.6\end{array}$ & $\begin{array}{r}26.9 \\
90.5 \\
64.2 \\
140.5 \\
203.8 \\
140.6\end{array}$ & $\begin{array}{c}47 \cdot 2 \\
103 \\
81 \cdot 2 \\
233.7 \\
218.7 \\
153.8\end{array}$ & $\begin{array}{r}13.6 \\
53.1 \\
69.9 \\
167 \cdot 3 \\
222 \cdot 5 \\
178.9\end{array}$ & & \\
\hline
\end{tabular}

The experiment was repeated with six rats maintained in the same mercury atmosphere for 100 hours a week for seven weeks. The rats showed toxic signs similar to those described in the previous experiment and two died during the seventh week. Death was preceded by loss of weight, fall of body temperature, and coma. Necropsy and histopathological examination showed congestion of the lungs and livers, and degeneration of the cortical tubules of one rat. Individual urine collections were taken from these rats during the exposure period, and the weekly totals of each rat are shown in Table 5 , together with the coefficients of variation of these totals round the weekly means.

Repeated Seven-hour Exposures.-Six rats were exposed to $1 \mathrm{mg}$./cu.m. mercury for seven hours a day, five days a week, for 18 successive weeks. The rats showed a slight increase in weight during this period but their rate of growth was much less than that of rats kept under similar conditions but in the absence of mercury vapour. After the seventh week the rats appeared lethargic and two squeaked when touched; by the fifteenth week these two rats showed fine tremors when lifted by their tails. At the end of the exposure period two rats were killed for organ analysis and the survivors soon returned to good condition and started to increase in weight more rapidly. Pooled urine was collected during and after exposure as described above, and analytical figures for urinary mercury are shown in Fig. 4. There was a slight fluctuating excretion of protein in urine with a maximum of $0.2 \mathrm{mg} . / \mathrm{ml}$. The surviving rats were killed at two and four months after exposure and the organ analyses are shown in Table 6.

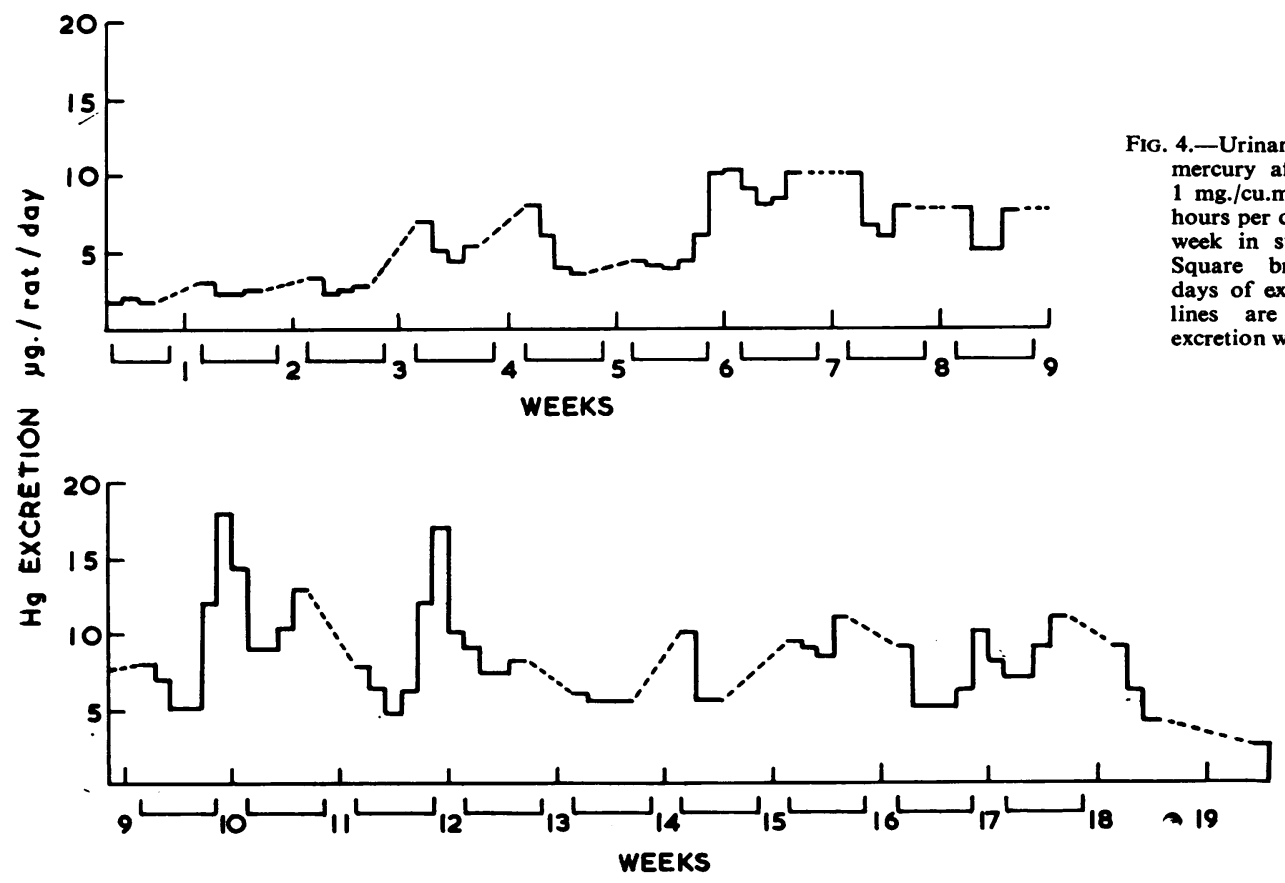


TABLE 6

MERCURY CONTENT OF ORGANS FROM RATS EXPOSED TO 1 mg./cu.m. MERCURY SEVEN HOURS A DAY, FIVE DAYS A WEEK, FOR 18 WEEKS; AVERAGE OF TWO RATS EXPRESSED AS $\mu \mathrm{g}$./RAT

\begin{tabular}{|c|c|c|c|c|c|}
\hline \multirow{2}{*}{$\begin{array}{c}\text { Period after } \\
\text { Exposure } \\
\text { (months) }\end{array}$} & \multicolumn{5}{|c|}{ Organs } \\
\hline & Lungs & Liver & Kidney & Spleen & Brain \\
\hline $\begin{array}{l}0 \\
2 \\
4\end{array}$ & $\begin{array}{l}1 \cdot 0 \\
0 \\
0\end{array}$ & $\begin{array}{l}0.7 \\
0 \\
0\end{array}$ & $\begin{array}{c}140 \\
14 \cdot 2 \\
0\end{array}$ & $\begin{array}{l}0 \cdot 1 \\
0 \\
0\end{array}$ & $\begin{array}{l}5 \cdot 3 \\
1 \cdot 9 \\
1 \cdot 3\end{array}$ \\
\hline
\end{tabular}

\section{Discussion}

The excretion of mercury by rats exposed to an atmosphere containing $1 \mathrm{mg}$./cu.m. mercury for four weeks, is shown in Fig. 2 and can be considered in three stages. During the first $\mathbf{1 0}$ days there is a progressive increase in the mercury excreted; this is followed during the remaining 18 days of exposure by a daily excretion fluctuating around a mean value, and after the termination of the exposure the excretion rapidly falls. The major contribution to this pattern of excretion is made by the urine and the faecal excretion shows less variation. It seems unlikely that the average of $15 \mu \mathrm{g}$. mercury per day in the faeces derives from ingestion and it may be attributed to an excretion into the gut.

The first phase of the excretion shown in Fig. 2 indicates a progressive accumulation of mercury in the body, while the central plateau corresponds to a "steady state" in which the body is saturated and absorption is equal to excretion. If the respiratory minute volume of the rat is taken to be $100 \mathrm{ml}$. (Gaddum, 1959), the total mercury content of the air inspired in 24 hours is in the region of $140 \mu \mathrm{g}$.; as the average daily excretion during the saturation stage is about $71 \mu \mathrm{g}$., the efficiency of retention of mercury by the lungs is approximately $50 \%$. Published figures for the retention of mercury in the lungs by man and the dog range between 15 and nearly $100 \%$ (Storlazzi and Elkins, 1941); in this laboratory experiments with isolated cat lungs artificially perfused with whole blood and ventilated with air containing $1 \mathrm{mg}$./cu.m. mercury, have shown that between 39 and $66 \%$ was retained by the lungs (Swan, 1960). It seems unlikely that the considerable fluctuation round the average value during the saturation stage can be attributed to a periodic variation in the efficiency of retention of mercury by the lungs, and it may derive from changes in the mercury retention by the body, or more probably in the magnitude of the respiratory minute volume. Adamo (1939) has shown that the increased respiratory volume attendant on an increased carbon dioxide content or humidity of the inspired air resulted in a greater absorption of mercury. This factor may also be a major contribution to the variation in the mercury excretion of individual rats exposed to $1 \mathrm{mg}$./cu.m. mercury for repeated 100 hour periods, which is shown in Table 5.

The total accumulation of mercury in the tissues during the first stage of the continuous exposure experiment shown in Fig. 2 can be estimated from the difference between the total excreted during this period and the total absorbed. If the daily absorption is assumed to be $71 \mu \mathrm{g}$. the figure so obtained is $370 \mu \mathrm{g}$. A direct determination of the amounts stored can also be obtained from the tissue analysis in Table 2; the first entry in the Table gives a total of $304 \mu \mathrm{g}$. which is in sufficiently good agreement with the figure quoted above, bearing in mind the errors involved, to make it likely that no significant reservoir of mercury has been missed.

At the termination of the continuous exposure the excretion of mercury does not immediately cease, due to a release of mercury stored in the tissues. During the first two-day period after exposure the body loses $104 \mu \mathrm{g}$. and during the second, $35 \mu \mathrm{g}$.; these figures agree well with the total excretion of 90.5 and $47.6 \mu \mathrm{g}$. during the same two periods (Fig. 2). As the bulk of the stored mercury is found in the kidneys, and most of the excreted mercury in the urine, the kinetics of excretion may be based on the assumptions that the daily loss from the body appears in the urine, and that this loss is proportional to the amount of mercury in the kidneys. The following equations may be written where $v$ is the amount in the kidneys, $u$ is the quantity of mercury excreted in urine in one day, $u_{o}$ is the initial value, and $\alpha$ is a constant.

$$
\begin{aligned}
-d v / d t & =u=a v \\
u & =u_{o} \mathrm{e}^{-\alpha t} \\
\log _{10} u & =\log _{10} u_{o}-\alpha t / 2 \cdot 3
\end{aligned}
$$

The nature of the post-exposure excretion is seen more clearly in Fig. 3; it approximates to the exponential pattern expected from equation (2) and the broken line in this Figure has been calculated from equation (3) with the constant $a$ given the empirical value $0 \cdot 4 /$ day.

During the initial period when mercury is accumulating in the tissues, the daily excretion of mercury in the urine is given by equations (4) and (5), where $a$ has the same value 0.4 and $u_{o}$ is the average daily excretion when saturation of the tissues is achieved.

$$
\begin{aligned}
u & =u_{o}\left(1-\mathrm{e}^{-\alpha t}\right) \\
\log _{10}\left(u_{o}-u\right) & =\log _{10} u_{o}-\alpha t / 2 \cdot 3
\end{aligned}
$$

The broken line in Fig. 2 is calculated on the assumption that the total excretion can be represented by equations (3) and (5), and $u_{o}=71 \mu \mathrm{g}$./day. The experimental post-exposure values agree well with this curve, but the values at the commencement 
of the exposure do not show the expected initial rapid increase; this deviation is more marked if the urinary excretion alone is compared with the theoretical curve with $u_{o}=56$. The urinary excretion in Fig. 2 shows a slow increase for the first few days followed by a more rapid rise; this tendency is also seen in the urinary excretion at the commencement of each weekly exposure period shown in Fig. 3, and it is still more marked in Fig. 4. This initial delay in excretion is not due to a delay in the accumulation of mercury in the kidney, for the analytical figures in Table 3 indicate a rapid increase in the amount of mercury in the kidney during the first few days of exposure. This Table also includes the values of the constant $\alpha$ from equation (1) during this period, calculated from the ratio between the amount in the kidney and the corresponding daily output in the urine. The value of $\alpha$ on the second day of exposure is much less than 0.4 and only reaches this value on the fourth day; this indicates that initially the mercury in the kidney is excreted more slowly and that the simple assumptions in equation (1) are inadequate completely to define the kinetics of mercury excretion.

It may be seen from Fig. 3 that when rats are exposed to $1 \mathrm{mg}$./cu.m. mercury for successive 100-hour periods, the peak urinary mercury excretion occurs at the end of the week and rises progressively until after four weeks it has reached an approximately constant value which is of the same order as the "steady state" urinary excretion in Fig. 2. This suggests that the tissues are then saturated and the mercury lost during the week-end when the rats are not exposed to mercury vapour is regained during the subsequent exposure. However, the results obtained from rats exposed for five daily seven-hour exposures each week (Fig. 4), show that the excretion of mercury in urine is more complex than this. In these experiments the values were found to decrease from Monday onwards and start again to show an increase only on the following Friday. When excretion measurements were made over the week-ends the peak excretion was found to occur during this period of non-exposure, this peak approaching the value of approximately $20 \mu \mathrm{g}$. which would be expected if the tissues were saturated. This observation suggests that the excretion of mercury does not immediately start to decrease when exposure ceases and that the unexpected excretory pattern is due to the combination of an initial delay in the rise of excretion and a terminal delay in the fall-off.

Tables 4 and 6 show that mercury can still be found in the kidneys up to six months after exposure. This is not to be expected from equation (3) which suggests that $90 \%$ of the mercury should be cleared within six days. This suggests that another mechanism involving a slower clearance from the kidney is also involved, and there is some indication of this in the terminal excretion of mercury in Fig. 2 where the lower values begin to diverge from the expected exponential curve. From Tables 4 and 6 the average loss from the kidney during the period three to six months after exposure is 1 to $2 \%$ per day, an amount too small to be measured with certainty in urine. The clearance of mercury from brain is even slower than from kidney and there can be no doubt that the tremors and hypersensitivity which were exhibited by the rats in these experiments were due to the affinity of the central nervous system for mercury. There are interesting analogies between these effects on rats and the reported signs of mercurialism in man.

It is evident from the investigation that the fate of inhaled mercury vapour is complex. The lungs seem to be a fairly efficient means of extracting the vapour from the air; it seems probable that a chemical reaction at the surface of the lungs is involved in the retention of the fraction absorbed as there is no evidence that the solubility of metallic mercury in the body fluids is high. The lung analyses shown in Table 2 indicate that the mercury is fairly rapidly cleared from the lung, and this is confirmed from other sources (Wirth, 1936). A small proportion of the mercury is excreted from the circulating blood through the gut but the bulk is taken out by the kidney, from which most is excreted within a week. Much less mercury is found in other tissues and its rate of clearance from all is rapid with the exception of brain where the excretion is very slow.

The slower clearance of mercury from the kidney at the commencement of exposure suggests that mercury arriving at the kidney is not immediately excreted but must first undergo a change of state or location. The peak urinary excretion which may occur after interruption of exposure suggests that this transformation or translation of mercury within the kidney is independent of the contemporaneous supply of mercury to the kidney, and that the excretory pattern refers to the absorption a few days previously. A different mechanism must be postulated for the slow excretion which still occurs after exposure; this may be due to an irreversible incorporation of mercury into the cell proteins and the rate of excretion may be connected with the metabolic turnover of protein. The establishment of these hypotheses must wait upon a detailed chemical and cytological study of the distribution of mercury in the kidney and its state of chemical combination in the kidney and in urine.

On the basis of these observations it is possible to 
speculate on the significance of urinary mercury measurements in the control of human exposure to mercury vapour. It has been suggested that after short-term exposure the mercury appearing in urine is related to the amount in the kidney which has been inhaled a few days previously. A single measurement of mercury in urine is not, therefore, related to the immediate atmospheric concentration, and in order to obtain an estimate of the total amount absorbed during a working week it is necessary to collect a seven-day sample including the week-end. If the results obtained with rats at $1 \mathrm{mg} . / \mathrm{cu} . \mathrm{m}$. can be applied to man breathing 10 cu.m. a day for five days of an atmosphere containing the maximal allowable concentration of $0.1 \mathrm{mg}$./ cu.m., then the daily absorption might be expected to be in the region of $500 \mu \mathrm{g}$., with a daily excretion during the working week well below this figure but with a total excretion over seven days of approximately $2.5 \mathrm{mg}$. If the total exposure had been of short duration the bulk of the mercury would be eliminated in a few days after exposure. The rat experiments have also indicated that if exposure to mercury vapour is maintained for several weeks there is a progressive conversion of the mercury in the kidney to a slowly diffusible form and it is conceivable that prolonged human exposure will result in the accumulation in the kidney of mercury in this type of combination, resulting in an excretion which is maintained for a considerable period after exposure and which may amount to several hundred $\mu \mathrm{g}$. per day. It does not seem necessary to postulate wide individual differences in the ability to absorb and retain mercury in order to account for the reported differences in the urinary excretion of men exposed to similar industrial conditions for it seems that much of this can be attributed to the complex nature of mercury excretion. The lack of a simple correlation between mercury excreted in urine and the mercury concentration in the atmosphere inhaled suggests that a threshold concentration for mercury in urine cannot be derived from an accepted maximal allowable concentration for mercury in air.

The application of urinary mercury determina- tions to assess the amount of mercury in the body, or to confirm a diagnosis of mercury poisoning, is also likely to be difficult. Studies of human excretion of mercury have led to the conclusion that a high value is of diagnostic significance only when symptoms and signs of poisoning can be demonstrated (Bidstrup, Bonnell, Harvey, and Locket, 1951). The mercury appearing in urine is related to the mercury content of the kidney and there is no reason to suppose that mercury located there can harm any organ other than the kidney itself. More information would be provided by a knowledge of the state of combination of mercury in the kidney, as this might enable an assessment of the duration of exposure to be made which would indicate whether there had been an opportunity for mercury to enter the central nervous system. At present the only way of investigating this appears to be by repeated measurements of the excretion in urine after exposure has ceased, but the interpretation of the results so obtained requires more knowledge of the kinetics of human excretion. Another approach would be through a qualitative study of urine, if it could be shown that the transient and slow excretions were reflected in different states of chemical combination of mercury in urine.

I am indebted to Dr. J. G. S. Crabbe for a pathological report on the tissue sections, and to Mr. Z. S. Berczy for skilled technical assistance.

\section{REFERENCES}

Adamo, M. (1939). Rass. Med. industr., 10, 684.
Ashe, W. F., Largent, E. J., Dutra, F. R., Hubbard, D. M., and Blackstone, M. (1953).' Arch. industr. Hyg., 7, 19.

Bidstrup, P. L., Bonnell, J. A., Harvey, D. G., and Locket, S. (1951). Lancet, $2,856$.

Donaldson, H. H. (1924). "The Rat", 2nd ed. Mem. Wistar Inst. Anat., No. 6. Philadelphia.

Fabre, R., Truhaut, R., and Boudène, C. (1958). Ann. Biol. clin., 16,

Gaddum, J. H. (1959). Pharmacology, 5th ed. Oxford University Press, London.

Heyroth, F. F. (1949). Industrial Hygiene and Toxicology, vol. II, ed. F. A. Patty. Interscience Publ., New York.

Storlazzi, E. D., and Elkins, H. B. (1941). J. industr. Hyg., 23,

Swan, A. A. B. (1960). Personal communication.

Totušek, J., and Waelschová, A. (1954). Pracov. Lék., 6, 99.

Turrian, H., Grandjean, E., and Turrian, V. (1956). Schweiz. med. Wschr., 86, 1091 .

Wirth, W. (1936). Naunyn-Schmiedeberg's Arch. exp. Path. Pharmak., 